\title{
Assessment of Energy Lost in the Winding in Road Vehicle IPM Machines, Considering Saturation, Cross Coupling, Battery State of Charge
}

\author{
A. Di Gerlando, G. M. Foglia, R. Perini, B. Massa
}

\begin{abstract}
The paper proposes a method for the energetic characterization of IPM machines, used in road vehicles. By means of an accurate magnetic model, the method takes into account the magnetic properties of an IPM machine (i.e., high saturation and cross coupling), and the dependence on the battery voltage. Moreover, thanks to a statistical approach, a fast way to account for the influence of battery state of charge is considered.
\end{abstract}

Index Terms-IPM machines, energy efficiency, battery state of charge.

\section{INTRODUCTION}

A good energetic characterization of electric motors used for road vehicles is a very important goal. In the literature, many efforts were devoted to average efficiency over drive cycle (AEDC) [1]. Usually, the methods are based on FEA [1]-[6], sometimes mixed with some type of optimization (e.g.: differential evolution algorithm [2] ). Often, a driving cycle equivalent points method is adopted, where the energy distribution of the traction machine over the driving cycle is represented by few equivalent points [3], [4]. Usually, the efficiency map in the wide torque-speed range is obtained by using flux-linkage and loss models [5], [6]. Interior permanent magnet synchronous machine (IPMSM) has been widely used in traction applications, thanks to its high efficiency, high power density, high constant power range [7]-[9]. For IPM machines, the energetic characterization is more difficult, since magnetic saturation and cross coupling are higher than in other machines; therefore, an accurate magnetic model is needed, able to account for these magnetic effects. Moreover, a small usage of FEA would be appealing, since when the FEM approach is adopted to evaluate the efficiency maps, high computational times are required.

Another important issue is the influence of battery state of charge on the current and the losses. As known, motors are usually operated in Maximum Torque Per Ampere condition (MTPA), as far as the inverter voltage can increase with the speed and within the insulation dielectric limits; once the limiting speed (base speed) is reached, field weakening (FW)

Lombardy Region Government, Italy, has partially funded the research with POR/FESR INPROVES grant (ID 241363).

A. Di Gerlando, G. M. Foglia and R. Perini are with Politecnico di Milano, Department of Energy, Italy, antonino.digerlando@polimi.it, gianmaria.foglia@polimi.it, roberto.perini@polimi.it.

B. Massa is with Marelli Europe S.p.A., Motorsport Business Line, Italy, bruno.massa@marelli.com is applied. If the DC bus is supplied by a battery, the DC voltage may decrease as the battery discharges, and also the base speed decreases. As a consequence, an operating point which was in MTPA region may move in FW region; magnetic flux decreases, a higher current is required for a given torque, and higher winding losses occur. The matter could be solved by introducing a DC-DC converter between the battery and the inverter [10]-[12]: the DC-DC stage can keep the DC bus voltage constant. But such a solution adds components, thus increases costs, losses and required room, and decreases the reliability of the system. [13] presents a control method which takes into account the battery voltage variation, but system efficiency is not evaluated. Thus, a method to evaluate system efficiency, taking into account the battery voltage variation, would be useful.

Here, a method is proposed to evaluate in a fast way the energy lost in the winding, taking into account the battery state of charge. The method is based on two elements:

- an accurate magnetic model [14], which allows to take into accounts some peculiarities of IPM machines, that is the high level of saturation and cross coupling effects; the same model also allows to take into account the dependence on the battery voltage;

- a statistical approach, which allows to consider in a fast way the influence of battery state of charge.

The method is applied to an example of drive cycle, of an IPM used for a road vehicle.

The paper develops as follows: Sec. I describes the considered IPM machine; Sec. II presents the machine model, and shows how expressing the current as a function of torque, speed, battery voltage; Sec. III describes the statistical approach adopted to quickly evaluate winding lost energy, taking into account battery voltage.

\section{THE MOTOR CONSIDERED IN THE ANALYSIS}

The analisys is applied to an 8-pole IPM machine, with Vshaped PMs. Considering current limits of the feeding inverters, the machine is supposed equipped with two threephase windings: each of them is distributed along half the stator periphery, and the two feeding current terns are in phase. Fig. 1 shows a cross section of one pole motor portion. Table I reports the main data of the machine; torque and power data refer to the whole machine; rated voltage and current of each winding refer to the operation in MTPA at base speed and rated torque.

In the following analysis, some calculation results will be shown for three values of torque $\left(T_{n}, 2 / 3 \cdot T_{n}, T_{n} / 3\right)$ and of battery voltage $\left(V b_{M A X}, V b_{\text {min }}, V b_{\text {mean }}=0.5 \cdot\left(V b_{M A X}+V b_{\text {min }}\right)\right)$. 
TABLE I

MAIN DATA OF THE CONSIDERED IPM MACHINE

\begin{tabular}{l|l}
\hline Rated line-line voltage $V_{n}\left[\mathrm{~V}_{\mathrm{rms}}\right]$ & 190 \\
\hline Rated current $I_{n}\left[\mathrm{~A}_{\mathrm{rms}}\right] ;$ rated power $P_{n}[\mathrm{~kW}]$ & $376 ; 180$ \\
\hline Rated torque $T_{n}[\mathrm{Nm}] ;$ base speed $N_{n}[\mathrm{rpm}]$ & $324 ; 5300$ \\
\hline Pole pair number $n ;$ PM type & $4 ; \mathrm{SmCo}$ \\
\hline Phase resistance $R_{p h}[\mathrm{~m} \Omega] ;$ rotor inertia $\left[\mathrm{kgm}^{2}\right]$ & $16.82 ; 0.035$ \\
\hline Maximum $V b_{M A X}$ and minimum $V b_{\min }$ battery voltage [V] & $700 ; 500$
\end{tabular}

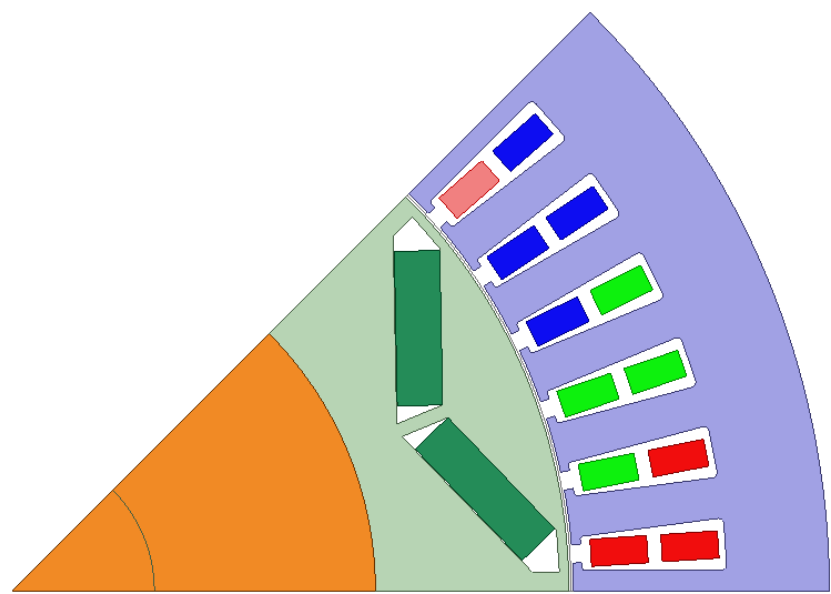

Fig. 1. One-pole cross section of the studied IPM machine.

\section{HOW EXPRESSING THE CURRENT AS A FUNCTION OF TORQUe, SPEED, BATTERY VOLTAGE}

\section{A. Machine model}

Let us define $\bar{\psi}_{s d q}=\psi_{s d}+j \psi_{s q}=\Psi_{s d q} \exp \left(j \varphi_{\psi}\right)$ the stator flux linkage space vector; $\bar{i}_{s d q}=i_{s d}+j i_{s q}=I_{s d q} \exp \left(j \varphi_{\mathrm{I}}\right)$ the stator current space vector; both $\psi_{s d q}$ and $\bar{i}_{s d q}$ are defined in $\mathrm{dq}$ reference frame, assuming $\mathrm{d}$ as the real axis; often, instead of the angle $\varphi_{\mathrm{I}}$, the angle $\gamma=\varphi_{I}-90 \mathrm{deg}$ is used.

In [14] an IPM model is described, which allows to take into account saturation and cross coupling effects accurately. The model is based on flux-current links, in particular on two FEM identified functions $\psi_{s d}\left(I_{s d q}, \varphi_{I}\right)$ and $\psi_{s q}\left(I_{s d q}, \varphi_{I}\right)$; then $\bar{\psi}_{s d q}$ becomes a function of $I_{s d q}$ and $\varphi_{I}$

$$
\bar{\psi}_{s d q}=\psi_{s d}\left(I_{s d q}, \varphi_{I}\right)+j \psi_{s q}\left(I_{s d q}, \varphi_{I}\right)=\psi_{s d q_{-} I \varphi}\left(I_{s d q}, \varphi_{I}\right)
$$

The stator voltage space vector $\bar{v}_{s d q}$ is obtained by the voltage law

$$
\begin{gathered}
\overline{v_{s d q}}=R_{p h} \cdot I_{s d q} \exp \left(j \varphi_{I}\right)+j \omega(N) \cdot \bar{\psi}_{s d q}\left(I_{s d q}, \varphi_{I}\right)= \\
=v_{s d q_{-} I \varphi}\left(I_{s d q}, \varphi_{I}, N\right)
\end{gathered}
$$

where $\omega(N)=2 \pi n N / 60, N$ is the speed in [rpm], $n$ is the pole pair number, $R_{p h}$ is the phase resistance (Tab I).

The electromagnetic torque $T e$ expression is the classical one, where the factor 2 accounts for the 2 terns, i.e.

$$
\begin{gathered}
T e=-2 \cdot n \operatorname{Im}\left[\psi_{s d q_{-} I \varphi}\left(I_{s d q}, \varphi_{I}\right) \cdot I_{s d q} \exp \left(-j \varphi_{I}\right)\right]= \\
=T e\left(I_{s d q}, \varphi_{I}\right)
\end{gathered}
$$

where $\operatorname{Im}()$ is the Imaginary part. By substituting $\varphi_{I}=\gamma+$ 90deg, $T e$ is expressed as a function of $I_{s d q}$ and $\gamma$ :

$$
\begin{aligned}
T e\left(I_{s d q}, \gamma\right)= & -2 \cdot n \operatorname{Im}\left[\psi_{s d q_{I} I}\left(I_{s d q}, \gamma+90 d e g\right)\right. \\
& \left.\cdot I_{s d q} \exp (-j(\gamma+90 d e g))\right]
\end{aligned}
$$

\section{B. Expressing voltage in MTPA operation as a function} of torque and speed

The current angle $\gamma_{M T P A}$, which gives the MTPA condition, can be obtained by performing a numerical derivative of (4) with respect to $\gamma$, and by zeroing such derivative. As a result, a function $\gamma_{M T P A_{-} I}\left(I_{s d q}\right)$ is gained, which gives $\gamma_{M P T A}$ as a function of $I_{s d q}$

$$
\begin{gathered}
\frac{\Delta T e\left(I_{s d q}, \gamma\right)}{\Delta \gamma}=\frac{T e\left(I_{s d q}, \gamma+\Delta \gamma\right)-T e\left(I_{s d q}, \gamma\right)}{\Delta \gamma} \\
\gamma_{\text {MTPA_I }}\left(I_{s d q}\right)=\text { zeroing }\left[\frac{\Delta T e\left(I_{s d q}, \gamma\right)}{\Delta \gamma}, \gamma\right] .
\end{gathered}
$$

By substituting (6) in (4), a function $T_{M T P A}\left(I_{s d q}\right)$ is obtained, which expresses the torque in MTPA operation as a function of $I_{s d q}$

$$
T_{M T P A}\left(I_{s d q}\right)=T e\left(I_{s d q}, \gamma_{M T P A} I\left(I_{s d q}\right)\right)
$$

By solving numerically the equation $T_{M T P A}\left(I_{s d q}\right)=T$ with respect to $I_{s d q}$, a function $I_{M T P A}(T)$ is obtained, which gives the current (amplitude of current space vector) in MTPA operation, as a function of the desired torque $T$

$$
I_{M T P A}(T)=\text { solve }\left[I_{s d q}, T_{M T P A}\left(I_{s d q}\right)=T\right]
$$

By inserting (8) in (6), a function $\gamma_{M T P A}(T)$ is obtained, which gives the angle $\gamma$ in MTPA operation, as a function of the desired torque $T$

$$
\gamma_{M T P A}(T)=\gamma_{M T P A_{-} I}\left(I_{M T P A}(T)\right) .
$$

Finally, by inserting (8) and (9) in (2), a function $V_{M T P A}(T, N)$ follows, which gives the voltage in MTPA operation (amplitude of voltage space vector), as a function of the desired torque and speed

$$
V_{M T P A}(T, N)=\left|v_{s d q_{-} I \varphi}\left(I_{M T P A}(T), \gamma_{M T P A}(T)+90 \operatorname{deg}, N\right)\right| \text {. }
$$

\section{Definition of boundary speed for MTPA operation}

A sinusoidal PWM is considered, for a three phase drive. As known, at the limit of the PWM linear region, the relation between the amplitude of the fundamental inverter phase voltage $V_{i 1 \text { peak }}$ and the DC bus voltage $V_{D C}$ is $V_{i 1 p e a k}=V_{D C} / 2$. If a voltage margin $\Delta V$ is assumed, the relation is modified in $V_{\text {ilpeak }}=\left(V_{D C}-\Delta V\right) / 2$. The boundary speed for MTPA operation occurs when the voltage in MTPA operation (10), scaled to peak phase voltage, equals the limit value of PWM linear operation, that is $V_{M T P A}(T, N) \cdot \sqrt{ } 2 / \sqrt{ } 3=\left(V_{D C}-\Delta V\right) / 2$. Solving such equation with respect to $N$ (by means of a numerical solving function), a function $N_{l i m}\left(T, V_{D C}\right)$ follows, which gives the maximum speed for MTPA operation, as a function of the desired torque and the battery voltage:

$$
N_{\text {lim }}\left(T, V_{D C}\right)=\operatorname{solve}\left[N, V_{M T P A}(T, N) \cdot \sqrt{ } 2 / \sqrt{ } 3=\left(V_{D C}-\Delta V\right) / 2\right]
$$


Fig. 2 shows three examples of the function $V_{M T P A}(T, N)$ $\sqrt{2} / \sqrt{3}$, for three values of torque, together with 3 values of the limit voltage $V_{i l p e a k}=\left(V_{D C}-\Delta V\right) / 2(\Delta V$ is assumed equal to $50 \mathrm{~V}$ ). It is apparent that the boundary speed decreases as the battery voltage decreases.

Fig 3 shows three examples of the function (11), for three values of battery voltage.

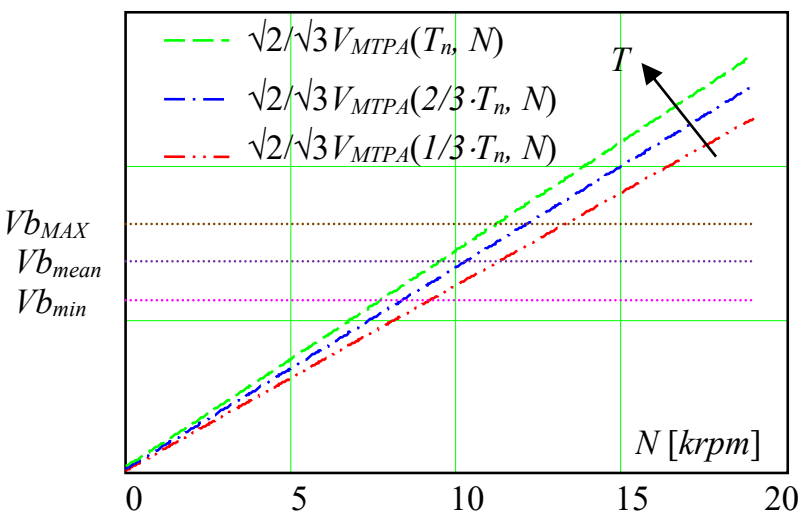

Fig. 2. Three examples of the function $V_{M T P A}(T, N) \cdot \sqrt{2} / \sqrt{ } 3$, for three values of torque, together with three values of the limit voltage $V_{\text {ilpeak }}=\left(V_{D C}-\Delta V\right) / 2$ ( $\Delta V$ is assumed equal to $50 \mathrm{~V}$ ).

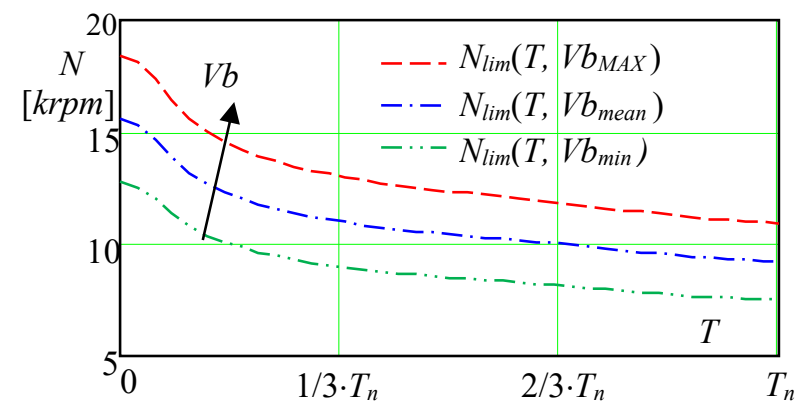

Fig 3. Three examples of the function (11), for three values of $V b$ voltage.

D. Expressing the current as a function of torque, speed and battery voltage

By numerically solving the equation $T e\left(I_{s d q}, \gamma\right)=T$ with respect to $I_{s d q}$, a function $I(T, \gamma)$ is obtained, which gives the current $I_{s d q}$ (amplitude of current space vector) as a function of the desired torque $T$ and angle $\gamma$

$$
I(T, \gamma)=\text { solve }\left[I_{s d q}, \quad T e\left(I_{s d q}, \gamma\right)=T\right]
$$

By inserting (12) in (2), $\bar{v}_{s d q}$ is expressed as a function of torque $T$, angle $\gamma$, speed $N$

$$
\overline{v_{s d q}}=v_{s d q_{-} T \gamma}(\mathrm{T}, \gamma, N)=v_{\text {sdq_L }}(\mathrm{I}(\mathrm{I}, \gamma), \gamma+90 \mathrm{deg}, N)
$$

As explained, the equation $\left|\overline{v_{s} d q}\right| \cdot \sqrt{ } 2 / \sqrt{ } 3=\left(V_{D C}-\Delta V\right) / 2$ identifies the maximum value of the inverter voltage for the operation in the PWM linear zone. If $\bar{v}_{s d q}$ is expressed by (13), and the former equation is solved with respect to the angle $\gamma$, a function $\gamma_{\text {Vlim }}\left(T, N, V_{D C}\right)$ is obtained, which gives the boundary value of angle $\gamma$ for the operation in the PWM linear zone:

$$
\begin{array}{r}
\gamma_{\text {Vlim }}\left(T, N, V_{D C}\right)=\text { solve }\left[\gamma,\left|v_{\text {sdq_L }}(T, \gamma, N)\right| \cdot \sqrt{2} / \sqrt{ } 3=\right. \\
\left.=\left(V_{D C}-\Delta V\right) / 2\right] \quad \cdot \quad(14)
\end{array}
$$

We assume that out of MTPA operation, the angle $\gamma$ equals $\gamma_{\text {Vlim }}$; in other words, we assume that out of MTPA zone, the current is given by a function $I_{\text {Vlim }}\left(T, N, V_{D C}\right)$ obtained by inserting (14) in (12)

$$
I_{\text {Vim }}\left(T, N, V_{D C}\right)=I\left(T, \gamma_{\operatorname{Vim}}\left(T, N, V_{D C}\right)\right) \text {. }
$$

The boundary for MTPA operation is given by $N_{\text {lim }}$ of (11). Thus, the relation which expresses the current as a function of torque, speed and battery voltage can be given by an if statement which selects between (8) and (15)

$$
I\left(T, N, V_{D C}\right)=i f\left(N<N_{\text {lim }}\left(N, V_{D C}\right), I_{M T P A}(T), I_{\text {Vlim }}\left(T, N, V_{D C}\right)\right)
$$

Fig. 4 shows three examples of the function (16) for three values of $V_{D C}$ and for three values of torque.

The y-axis scale is expressed in p.u. values, referred to $I_{M T P A}\left(T_{n}\right)$, that therefore becomes 1 .
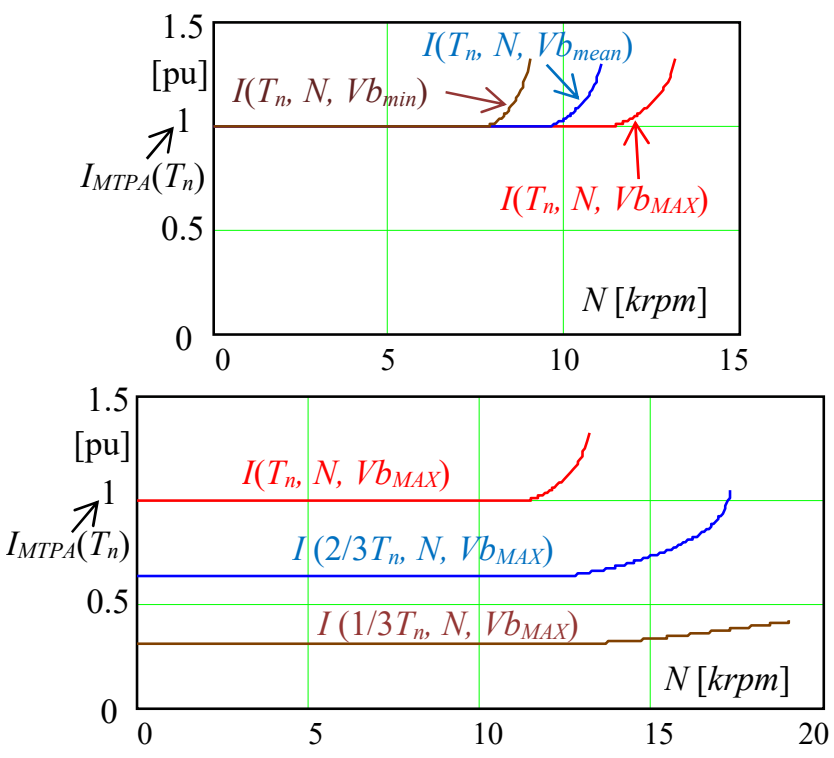

Fig. 4. Three examples of function (16) for three values of $V_{D C}$, with $T$ $=T_{n}$ (top), and for three values of torque, with $V b=V b_{M A X}$ (bottom). The yaxis scale is in p.u. values, referred to $I_{M T P A}\left(T_{n}\right)$, that therefore becomes 1 .

\section{StatisticAl Approach to QUiCKLy EVAlUATE} WINDING LOST ENERGY, CONSIDERING BATTERY VOLTAGE

The function (16) allows evaluating the winding Joule losses $\mathrm{P}_{\mathrm{J}}$ at any instant, as a function of torque, speed and battery state of charge:

$$
P_{J}\left(T, N, V_{D C}\right)=2 \cdot R_{p h} \cdot I\left(T, N, V_{D C}\right)^{2} .
$$

The factor 2 is due to the two three phase windings, while the factor 3 is absent, since in (16) the current is the amplitude of the current space vector (Park transform has been performed according to the constant power formulation rather than the constant current one). Fig. 5 shows an example of drive cycle, with torque and speed waveforms, and the related power. Since the cycle duration $\Delta t_{c}$ is usually little (in the example of Fig. 5 it equals $\Delta t_{c}=100 \mathrm{~s}$ ), we can assume that the battery voltage is constant during each cycle; with this assumption, Fig. 6 shows currents and Joule losses during the cycle, for three values of $V_{D C}$. As previously cited, during the battery discharge, the boundary speed for MTPA operation decreases, thus higher currents and higher winding losses occur for the same speed value. 

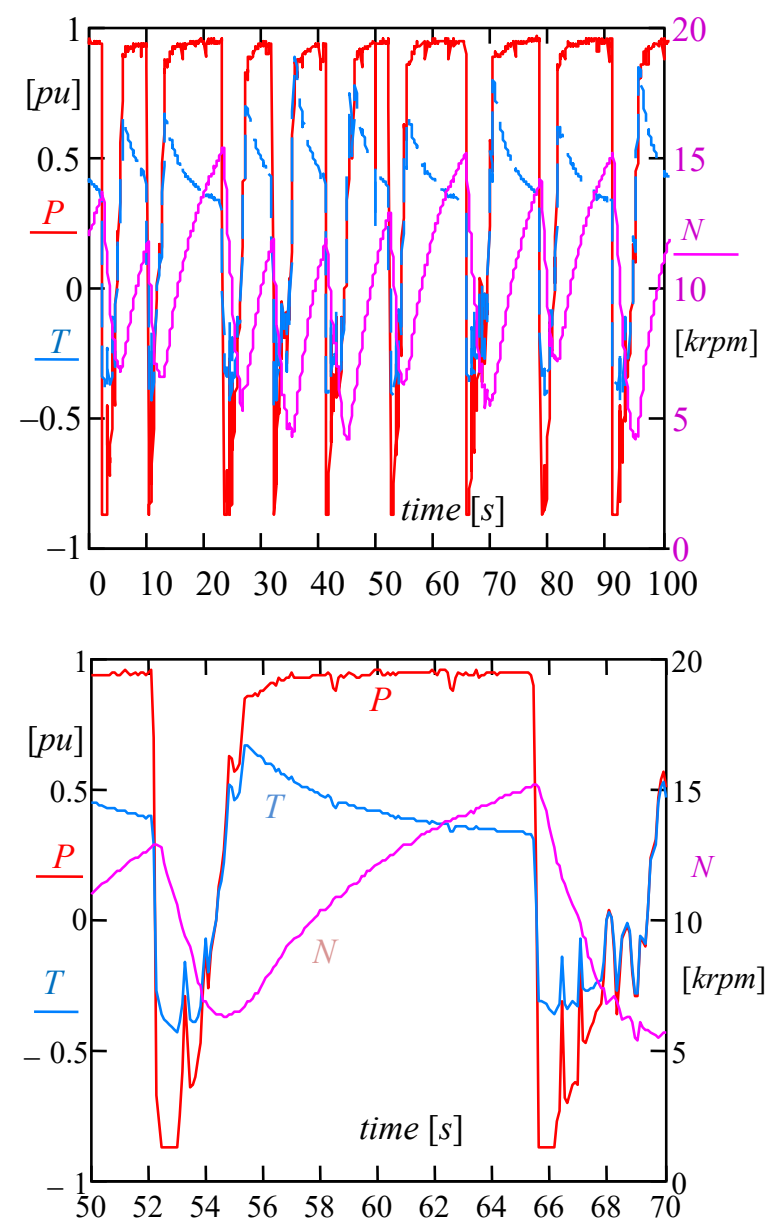

Fig. 5. Example of drive cycle, with torque, speed and power waveforms; the pu quantities are referred to the rated values in Tab. I

Let us consider the reference drive cycle (e.g., the one in Fig. 5) and let us assume that the total working time interval is made by the repetition of $N c$ cycles; the reference cycle lasts $\Delta t_{1 c}$, the total working interval lasts $N c \cdot \Delta t_{1 c}$. In all the cycles, the waveforms $T(t)$ and $N(t)$ are considered always the same, whereas the battery voltage $V_{D C}$ changes, due to the battery discharge.

The winding lost energy $L_{J}$ during the total working interval is given by the integral over $\Delta t_{c}=N c \cdot \Delta t_{1 c}$ of the Joule loss (17)

$$
L_{J}=\int_{0}^{N c \cdot \Delta_{1 c}} P_{J}\left(T(t), N(t), V_{D C}(t)\right) \cdot d t
$$

The whole interval can be split in the single cycles, thus $L_{J}$ is the summation of the energy lost of each cycle $L_{J k}$ :

$$
L_{J}=\sum_{k=1}^{N c} L_{J k}=\sum_{k=1}^{N c} \int_{k \cdot \Delta t_{1 c}}^{(k+1) \cdot \Delta t_{1 c}} P_{J}\left(T(t), N(t), V_{D C}(t)\right) \cdot d t
$$

Now, let us assume that the battery voltage remains almost constant during each k-th cycle. Remembering that the waveforms $T(t)$ and $N(t)$ are always the same, in the integral (19) and for each cycle $k, V_{D C k}$ is a constant value.

Therefore, we can introduce a function $L_{J 1 c}\left(V_{D C}\right)$ which gives the winding lost energy during one drive cycle as a function of just the battery voltage $V_{D C}$ :
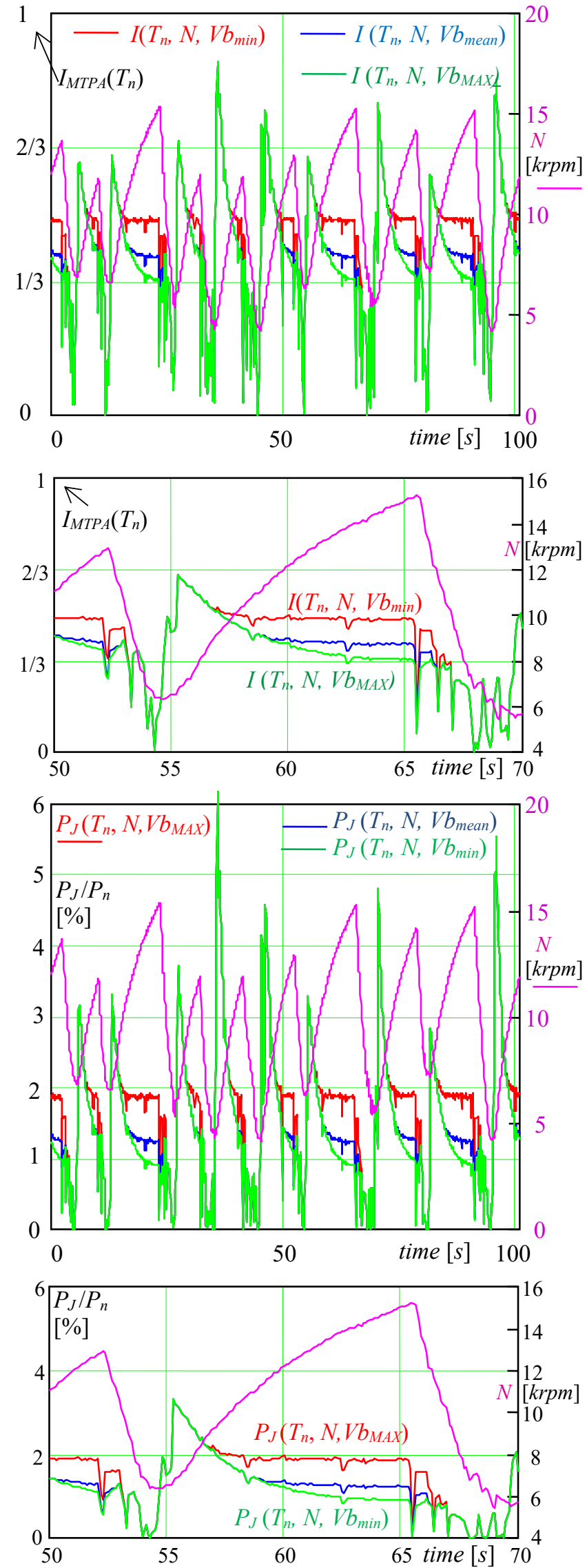

Fig. 6. Currents (top) and Joule losses (bottom) for Fig. 5, for three $V_{D C}$ values. The current reference value is $I_{M T P A}\left(T_{n}\right)$, that therefore becomes 1 . 


$$
L_{J 1 c}\left(V_{D C}\right)=\int_{0}^{\Delta_{1 c}} P_{J}\left(T(t), N(t), V_{D C}\right) \cdot d t \quad .
$$

The function $L_{J 1 c}\left(V_{D C}\right)$ can be gained quickly, by evaluating the integral in (20) for a few values $V_{D C}$, and interpolating these points by a spline; Fig. 7 shows an example of such calculations, with the data of Fig. 6. By means of the function $L_{J 1 c}\left(V_{D C}\right), L_{J}$ can be expressed as

$$
L_{J}=\sum_{k=1}^{N c} L_{J 1 c}\left(V_{D C k}\right)
$$

Now, let us consider $N_{V D C}$ voltage values $V_{D C i}(i=1$.. $N_{V D C}$ ) between the maximum $V_{D C M A X}$ and minimum $V_{D C m i n}$ of the battery voltage $V_{D C}$; each value equals $V_{D C i}=V_{D C m i n}+$ $i \cdot\left(V_{D C M A X}-V_{D C \min }\right) / N_{V D C}$. Moreover, let us assume that the values $V_{D C k}$ in (21) are chosen among the values $V_{D C i}$. Along the whole working interval ( $N c$ cycles), each value $V_{D C i}$ occurs $N_{i}$ times; thus, $L_{J}$ can also be expressed as

$$
L_{J}=\sum_{i=1}^{N_{V D C}} L_{J 1 C}\left(V_{D C}\right) \cdot N_{i}
$$

Since the function $L_{J 1 c}\left(V_{D C}\right)$ is known, once the values $N_{i}$ are known for any $V_{D C i}$ value, $L_{J}$ evaluation is immediate.

This is a very quick way to estimate winding lost energy, taking into account the battery voltage change.

As an example, for the considered motor, Tab II gives the voltage values $V_{D C i}$ and the corresponding $N_{i}$ occurrences. With the $L_{J 1 c}\left(V_{D C}\right)$ function of Fig. 7 and the $N_{i}$ values of Tab. II, we get $L_{J}=27 \mathrm{MJ}$ (for $N c=100$ cycles).

TABLE II

Voltage VALUES $V_{D C i}[\mathrm{~V}]$ AND CORRESPONDING $N_{i}$ OCCURRENCES

\begin{tabular}{l|r|r|r|r|r|r|r|r|r|r|r}
\hline$V_{D C i}$ & 500 & 510 & 520 & 530 & 540 & 550 & 560 & 570 & 580 & 590 & 600 \\
\hline$N_{i}$ & 0 & 0 & 1 & 2 & 3 & 3 & 4 & 4 & 5 & 6 & 9 \\
\hline$V_{D C i}$ & 600 & 610 & 620 & 630 & 640 & 650 & 660 & 670 & 680 & 690 & 700 \\
\hline$N_{i}$ & 9 & 11 & 13 & 11 & 9 & 8 & 6 & 4 & 1 & 0 & 0 \\
\hline
\end{tabular}

Eq. (22) can be interpreted in another way: in fact, $\Sigma N_{i}=$ $N c$, thus the ratio $N_{i} / N c$ is the frequency $f_{i}$ of the value $V_{D C i}$. Let us define a function $f\left(V_{D C i}\right)$ which gives $f_{i}$ for any $V_{D C i}$. $L_{J}$ can be expressed as:

$$
L_{J}=N C \cdot \sum_{i=1}^{N_{V D C}} L_{J 1 C}\left(V_{D C}\right) \cdot f\left(V_{D C i}\right) .
$$

If $N_{V D C}$ tends to infinite, and we move from a summation to an integral, the function $f\left(V_{D C i}\right)$ can be interpreted as the Weibull distribution $f_{W}\left(V_{D C}\right)$ of the battery voltage, and $L_{J}$ can be expressed as

$$
L_{J}=N c \cdot \int_{V_{D C \min }}^{V_{D C M X}} L_{J 1 c}\left(V_{D C}\right) \cdot f_{W}\left(V_{D C}\right) \cdot d V_{D C}
$$

\section{CONCLUSION}

The paper presents a method to evaluate the energy lost in the winding of an IPM motor, used for a road vehicle. Two are the peculiarities of the method: the quickness and the ability to take into account the variation of the battery voltage during the working interval. The method can be used for the assessment of the efficiency of the traction motor along the whole working interval.

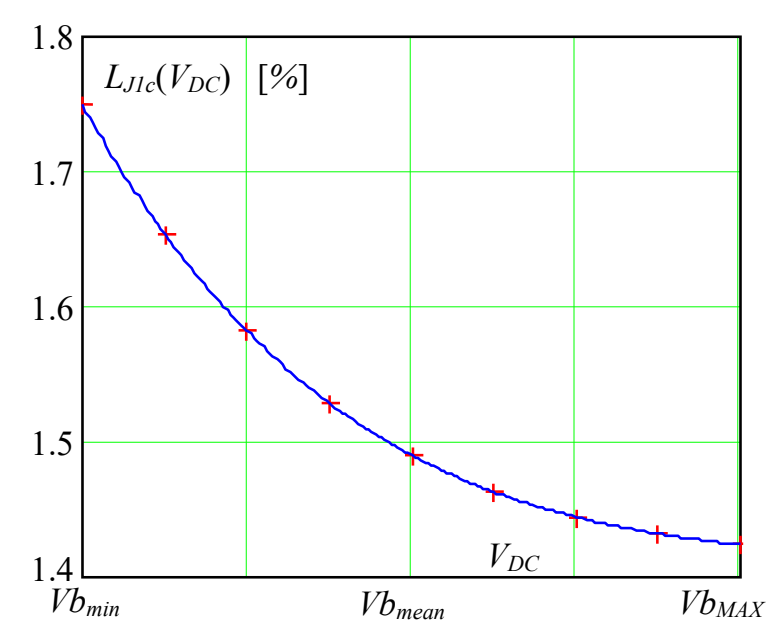

Fig. 7. Winding lost energy $L_{J 1 C}\left(V_{D C}\right)$ in one cycle as a function of the battery voltage $V_{D C}$ : the function has been obtained by interpolating some points $(+)$, calculated by the integral (20). The $L_{J 1 c}$ values are expressed in percentage, referred to $L_{r e f}=P_{n} \cdot \Delta t_{1 c}=18 \mathrm{MJ}$. The functions $T(t)$ and $N(t)$ are the ones of Fig. 5, and the corresponding winding power losses are those of Fig. 6.

\section{REFERENCES}

[1] Q. Li, T. Fan, X. Wen, Y. Li, Z. Wang and J. Guo, "Design optimization of interior permanent magnet synchronous machines for traction application over a given driving cycle," IECON 2017 - 43rd Annual Conference of the IEEE Industrial Electronics Society, Beijing, 2017, pp. 1900-1904. doi: 10.1109/IECON.2017.8216321

[2] S. Günther, S. Ulbrich and W. Hofmann, "Driving cycle-based design optimization of interior permanent magnet synchronous motor drives for electric vehicle application," 2014 International Symposium on Power Electronics, Electrical Drives, Automation and Motion, Ischia, 2014, pp. 25-30. doi: 10.1109/SPEEDAM.2014.6872108

[3] L. Chen, J. Wang, P. Lazari and Xiao Chen, "Optimizations of a permanent magnet machine targeting different driving cycles for electric vehicles," 2013 Intern. Electric Machines \& Drives Confer., Chicago, IL, 2013, pp. 855-862. doi: 10.1109/IEMDC.2013.6556198

[4] E. Carraro, M. Morandin, and N. Bianchi, "Traction PMASR Motor Optimization According to a Given Driving Cycle," IEEE Transactions on Industry Applications, vol. 52, no. 1, pp. 209-216, 2016.

[5] S. Stipetic and J. Goss, "Calculation of efficiency maps using scalable saturated flux-linkage and loss model of a synchronous motor," 2016 XXII Intern. Conference on Electrical Machines (ICEM), Lausanne, 2016, pp. 1380-1386. doi: 10.1109/ICELMACH.2016.7732704

[6] J. Goss, P. H. Mellor, R. Wrobel, D. A. Staton and M. Popescu, "The design of AC permanent magnet motors for electric vehicles: A computationally efficient model of the operational envelope," 6th IET International Conference on Power Electronics, Machines and Drives (PEMD 2012), Bristol, 2012, pp. 1-6. doi: 10.1049/cp.2012.0251

[7] P. B. Reddy, A. M. El-Refaie, K. Huh, J. K. Tangudu and T. M. Jahns, "Comparison of Interior and Surface PM Machines Equipped With Fractional-Slot Concentrated Windings for Hybrid Traction Applications," in IEEE Transactions on Energy Conversion, vol. 27, no. 3, pp. 593-602, Sept. 2012. doi: 10.1109/TEC.2012.2195316

[8] N. Bianchi, S. Bolognani, and P. Frare, "Design criteria for highefficiency SPM synchronous motors," Energy Conversion, IEEE Transactions on, vol. 21, no. 2, pp. 396-404, 2006.

[9] A. Tessarolo, M. Mezzarobba and R. Menis, "Modeling, Analysis, and Testing of a Novel Spoke-Type Interior Permanent Magnet Motor with Improved Flux Weakening Capability," in IEEE Transactions on Magnetics, vol. 51, no. 4, pp. 1-10, April 2015, Art no. 8103910. doi: 10.1109/TMAG.2014.2357225

[10] J. O. Estima and A. J. Marques Cardoso, "Efficiency Analysis of Drive Train Topologies Applied to Electric/Hybrid Vehicles," in IEEE Transactions on Vehicular Technology, vol. 61, no. 3, pp. 1021-1031, March 2012. doi: 10.1109/TVT.2012.2186993

[11] M. O. Badawy, T. Husain, Y. Sozer and J. A. De Abreu-Garcia, "Integrated Control of an IPM Motor Drive and a Novel Hybrid Energy Storage System for Electric Vehicles," in IEEE Transactions 
on Industry Applications, vol. 53, no. 6, pp. 5810-5819, Nov.-Dec. 2017. doi: 10.1109/TIA.2017.2741438

[12] W. Deng, Y. Zhao and J. Wu, "Energy Efficiency Improvement via Bus Voltage Control of Inverter for Electric Vehicles," in IEEE Transactions on Vehicular Technology, vol. 66, no. 2, pp. 1063-1073, Feb. 2017. doi: 10.1109/TVT.2016.2555990

[13] B. Kim, M. Kwak, T. Chung, Y. Lee and J. Jung, "A method for improving HEV motor system efficiency considering battery voltage variation," 8th International Conference on Power Electronics - ECCE Asia, Jeju, 2011, pp. 677-682. doi: 10.1109/ICPE.2011.5944639

[14] A. Di Gerlando, G.M. Foglia, R. Perini, "Procedure to Define an Accurate Model for Saturation and Cross-Coupling in IPM Machines", submitted to ICEM 2020

\section{BIOGRAPHIES}

Antonino Di Gerlando received his MS degree in electrical engineering from the Politecnico di Milano, Italy, in 1981. Currently, he is a Full Professor at the Department of Energy at Politecnico di Milano. Fields of interest: design and modeling of electrical machines, converters and drive systems. He is a senior member of IEEE and a member of the Italian Association of the Electric and Electronic Engineers (AEI).

Giovanni Maria Foglia received his MS degree and the $\mathrm{PhD}$ in electrical engineering at Politecnico di Milano, Milano, Italy, in 1997 and 2000.

Currently, he is an Associate Professor at the Department of Energy at Politecnico di Milano, and his main field of interest is the analysis and design of PM electrical machines.

Roberto Perini (M'10) received his MS degree and the $\mathrm{PhD}$ in electrical engineering from the Politecnico di Milano, Milano, Italy.

Currently, he is an Associate Professor at the Department of Energy at Politecnico di Milano. His interests are in the design and modeling of electrical machines and power electronics.

Bruno Massa received his MS degree in Mechanical Engineering at Politecnico di Milano, Milano, Italy, in 1998 and the PhD in Biomedical Robotics at Scuola Superiore Sant'Anna, Pisa, Italy, in 2002.

Currently, he is Mechatronics Manager at the Motorsport Business Line of Marelli Europe S.p.A. 